\title{
Atuação dos enfermeiros no cuidado às mulheres em situação de abortamento em uma maternidade pública de Teresina-PI
}

Nurses 'performance in caring women in abortion situation in a public maternity in Teresina-PI

Desempeño de las enfermeras en el cuidado de mujeres en situación de aborto en una maternidad pública en Teresina-PI

Rosane da Silva Santana

ORCID: https://orcid.org/0000-0002-0601-8223 Universidade Federal do Ceará, Brasil E-mail: rosane_santana5@hotmail.com

Marciano de Almeida Cruz Assunção ORCID: https://orcid.org/0000-0001-6941-5501 Centro Universitário Maurício Nassau, Brasil E-mail:marcianoa217@gmail.com

Erilayne Thais de Araujo ORCID: https://orcid.org/0000-0002-4196-1233 Centro Universitário Maurício Nassau, Brasil E-mail: erythais12@gmail.com

Maria do Amparo Ferreira Santos e Silva ORCID: https://orcid.org/0000-0003-3758-4778 Hospital Universitário do Piauí, Brasil. E-mail: enfamparofss@hotmail.com

Francisco Ricardo de Alcântara ORCID: https://orcid.org/0000-0003-4422-2652 Centro Universitário Maurício de Nassau, Brasil E-mail: ricardoalcantara94@hotmail.com Edilice da Costa Silva ORCID: https://orcid.org/0000-0003-2220-690X Centro Universitário Maurício de Nassau, Brasil E-mail: edilicecosta@hotmail.com

Nivia Cristiane Ferreira Brandão Soares ORCID: https://orcid.org/0000-0001-9284-6393 Universidade Federal do Maranhão. Brasil E-mail: niviacristianny@ hotmail.com

Francisca Jéssica Abreu da Silva ORCID: https://orcid.org/0000-0002-3877-6109 Centro Universitário Maurício Nassau, Brasil E-mail: jessicasillva_@hotmail.com

Katiana Rosa da Costa

ORCID: https://orcid.org/0000-0002-0651-5166 Centro Universitário Maurício Nassau, Brasil E-mail:katycosta62@gmail.com

Bruna Ferreira Vaz

ORCID: https://orcid.org/0000-0003-1879-9992 Centro Universitário Santo Agostinho, Brasil E-mail:brunalfvaz@gmail.com

Taciane Aparecida Dias dos Santos ORCID: https://orcid.org/0000-0002-1851-1648 Faculdade do Meio Norte, Brasil

E-mail:Taciane-Aparecida-15@ hotmail.com

\begin{abstract}
Resumo
Na contemporaneidade são vários os fatores que afetam a saúde da mulher, dentre eles, as taxas de abortamento, que apresentam índices elevados, principalmente nos países emergentes. No Brasil, o número de abortos legais e ilegais tem crescido e vem gerando sérios problemas de Saúde Pública. O objetivo da pesquisa foi conhecer os cuidados dos enfermeiros às mulheres em situação de abortamento. Estudo descritivo com abordagem qualitativa realizada nas unidades de internação de uma maternidade municipal pública de Teresina-PI. Os sujeitos da pesquisa foram 12 enfermeiros que prestavam cuidados às mulheres. Foram incluídos enfermeiros assistenciais e do quadro de profissionais efetivos e, excluídos apenas os que estavam de férias ou licença durante a realização da pesquisa. Para a coleta dos dados, utilizou-se roteiro de entrevista semiestruturado e os dados foram analisados por meio da técnica de
\end{abstract}


Análise de Conteúdo. Identificou-se os principais cuidados realizados pelos enfermeiros às pacientes em situação de abortamento eram voltados ao acolhimento, ao controle da intensidade do sangramento e ao apoio emocional. Quanto à atenção do cuidado destinado às mulheres, verificou-se que nem todos os profissionais desempenhavam os cuidados de forma humanizada, principalmente os aspectos psicológicos. Para que os cuidados às mulheres sejam integrais e humanizados como proposto pela Norma Técnica Humanizada ao abortamento do SUS, é necessário que todos os profissionais de saúde, em especial, os enfermeiros estejam integrados tanto na prestação de cuidados físicos com embasamentos técnicos, éticos e jurídicos na área do aborto, quanto nos cuidados psicológicos com escuta qualificada, afetividade e o acolhimento.

Palavras-chave: Abortamento; Cuidados de enfermagem; Enfermeiros; Saúde da mulher; Serviços de saúde.

\begin{abstract}
Currently, there are several factors that affect women's health, among them, abortion rates have high rates, especially in emerging countries. In Brazil, the number of legal and illegal abortions has been growing and has been generating serious public health problems. The objective of the research was to know the care of nurses to women in abortion. It's a descriptive study with a qualitative approach conducted in the hospitalization units of a public municipal maternity hospital in Teresina-PI. The research survey participants were 12 nurses who cared for women. Care nurses and staff were included, and only those who were on vacation or on leave during the research were excluded. For data collection, a semi-structured interview script was used and the data were analyzed using the Content Analysis technique. It was identified that the main care provided by nurses to aborted patients was focused on welcoming, controlling the intensity of the bleeding and emotional support. in a humanized way, especially the psychological aspects. For the care of women to be comprehensive and humanized as proposed by the Humanized Technical Standard on abortion of the SUS, it is necessary that all health professionals and special nurses, be integrated both in the provision of physical care with technical, ethical and legal basis. abortion area, as well as psychological care with qualified listening, affection and welcoming.
\end{abstract}

Keywords: Abortion; Nursing care; Nurses; Women's health; Health services.

\title{
Resumen
}

Actualmente, existen varios factores que afectan la salud de las mujeres, entre ellos las tasas de aborto, que tienen tasas elevadas, especialmente en los países emergentes. En Brasil, el número de abortos legales e ilegales ha crecido y ha generado graves problemas de salud pública. El objetivo de la investigación fue conocer el cuidado de las enfermeras a las mujeres en situación de aborto. Estudio descriptivo con abordaje cualitativo realizado en las unidades de internación de una maternidad pública municipal de Teresina-PI. Los sujetos de investigación fueron 12 enfermeras que brindaron atención a las mujeres. Se incluyeron enfermeras auxiliares y personal permanente, y solo se excluyeron aquellos que estaban de vacaciones o de baja durante la investigación. Para la recolección de datos se utilizó un guión de entrevista semiestructurado y los datos se analizaron mediante la técnica de Análisis de Contenido. Se identificó la principal atención brindada por enfermeras a pacientes en situación de aborto, orientada a acoger, controlar la intensidad del sangrado y el apoyo emocional. En cuanto a la atención brindada a las mujeres, se encontró que no todos los profesionales realizaban la atención de manera humanizada, especialmente en los aspectos psicológicos. Para que la atención a la mujer sea integral y humanizada como propone la Norma Técnica Humanizada para el aborto del SUS, es necesario que todos los profesionales de la salud, en especial las enfermeras, estén integrados tanto en la prestación del cuidado físico con bases técnicas, éticas y legales en el área del aborto, así como en la atención psicológica con escucha calificada, cariño y acogida.

Palavras clave: Aborto; Cuidado de enfermera; Enfermeras; La salud de la mujer; Servicios de salud.

\section{Introdução}

Na contemporaneidade são vários os fatores que afetam a saúde da mulher, dentre eles, as taxas de abortamento, que apresentam índices elevados, principalmente nos países emergentes. No Brasil, o número de abortos legais e ilegais tem crescido e vem gerando sérios problemas de Saúde Pública. Esta é uma prática universal, uma vez que há evidências de que aproximadamente $50 \%$ dos abortos identificados são provocados, e os ambientes dos quais são efetivados encontram-se precários, sobretudo nos países onde há leis restritivas (Strefling, Lunardi Filho, Demori, Soares \& Santos, 2015a).

O abortamento é o cessar da gravidez com a ejeção do produto da fecundação com peso menor ou igual a 500 gramas e com dimensões inferiores a 25 centímetros (Silva et. al., 2015). Nessa perspectiva existe uma série de debates polêmicos, considerando que se trata de vidas humanas, destacando-se a complexidade do tema para os profissionais da saúde. São vários os países que adotam medidas de refreamento na jurisprudência, com isso, há um alto número de mortes de mães que por 
motivos diversos resolvem interromper a gravidez de forma clandestina (Strefling, Lunardi Filho, Kerber, Soares \& Ribeiro, $2015 b)$.

De acordo com a legislação brasileira, há três formas legais de abortamento: quando não há outra forma de salvar a vida da mãe em decorrência da gestação; gravidez proveniente de estupro; e na detecção de patologia congênita do tipo anencefalia no feto. Mesmo existindo esse direito, muitas mulheres desconhecem a legalidade deste ato, implicando na utilização de estabelecimentos ilegais e por conseguinte aumentando os riscos de danos irreversíveis (Paes, Borges \& Rocha, 2018).

Devido às restrições impostas pela lei $\mathrm{n}^{\circ} 2.848 / 40$, o número ou tipo de aborto torna-se pouco conhecido e sua amplitude vai além dos casos notificados (Lima et. al., 2017). As clínicas clandestinas têm crescido cada vez mais no Brasil, tornando as mulheres mais vulneráveis e suscetíveis ao risco de morte ou lesões não reversíveis em decorrência do processo de abortamento, logo, na grande maioria das vezes é praticado por profissionais com pouca ou nenhuma qualificação para esta eventualidade (Maranhão, Gomes \& Barros, 2016).

Com as leis restritivas existentes no Brasil, a perspectiva da criminalização do aborto e seus altos índices de clandestinidade dificultam a compreensão sobre as dimensões e complexidade dessas práticas e consequentemente não contribuem para a diminuição do número de abortamentos realizados e ainda cooperam para a prática insegura, resultando em risco à vida de mulheres (Santana; Santos \& Pérez, 2014).

O Ministério da Saúde (MS) lançou em 1983 a Política Nacional de Saúde da Mulher com intuito de reduzir os danos provocados. Na situação de abortamento, a maternidade, local destinado ao atendimento específicos às mulheres, devem ter profissionais de saúde capacitados para o acolhimento com escuta privilegiada, respeitando sempre a fala de cada mulher, até mesmo quando não é explícita verbalmente, prestando assistência humanizada, mantendo a mulher sempre informada sobre a necessidade de cada intervenção, identificando e avaliando suas dificuldades e ameaças de cada uma delas, garantindo o sigilo das informações (Brasil, 2011).

Dentro desse contexto, Rodrigues, Andrade, Dantas e Silva, (2017) apontam a necessidade e a importância da aplicação de um Protocolo de enfermagem na assistência às mulheres em processo de abortamento para que seja realizado um atendimento de enfermagem mais específico, enfatizando a assistência do enfermeiro. Nesse protocolo constam ações acerca da realização do acolhimento humanizado, sobre o histórico de enfermagem, exame físico preciso, implementação de diagnósticos de enfermagem, ações assistenciais, orientações sobre as necessidades de cada conduta realizada, oferta de apoio psicológico, assistência social e adesão ao tratamento.

Torna-se significativo que os profissionais de saúde que atendem as mulheres em processo de abortamento, em específico a equipe de enfermagem, estejam preparados para oferecer qualidade da assistência de forma integral à mulher, principalmente no âmbito hospitalar, pois na maioria das vezes o atendimento ofertado é desumanizado. Tal acontecimento é averiguável em análise relatadas pelos próprios funcionários mais sensibilizados e que têm compromisso com a ética profissional e social, ou por familiares e pessoas que fazem visitas a essas mulheres (Soares, Feliciano \& Gobira, 2018).

Por conseguinte, a enfermagem é ciente da responsabilidade que tem de prestar um serviço de excelência ao seu cliente, ao estabelecimento no qual presta serviço, aos princípios que a norteiam, ao estatuto e normas da profissão. Desse modo, contribui significativamente no progresso de reconhecimento do cuidado e contentamento dos pacientes (Freitas, Camargo Silva, Minamisaya, Bezerra \& Sousa, 2014).

Os profissionais de enfermagem, principalmente o enfermeiro, atuam diretamente no cuidado a mulheres em situação de abortamento dentro de instituições de saúde, portanto compreender como o cuidado a estas mulheres vêm sendo realizado e praticado possibilita uma visão ampla sobre essa assistência, que, se não realizada de forma adequada e com qualidade, interfere de modo negativo na vida dessas mulheres, indo contra a premissa de que condutas em saúde precisam ser 
humanizadas e ter qualidade. Assim, o objetivo do estudo foi conhecer os cuidados dos enfermeiros às mulheres em situação de abortamento em uma maternidade pública de Teresina-PI.

\section{Metodologia}

Neste estudo, utilizou-se a abordagem qualitativa do tipo descritiva. Uma das principais potencialidades da pesquisa qualitativa é o desvelamento dos sentidos que orientam as ações e as interações humanas e que tem objetivos de aprofundar a compreensão do subjetivo, estudando ações dos indivíduos, grupos ou organizações em seu contexto social (Taquette \& Vilella, 2017).

O estudo foi realizado nas unidades de internação de uma maternidade municipal pública em Teresina-PI, após a autorização do Comitê de Ética em Pesquisa (CEP) da Faculdade de Ciências e Tecnologia do Maranhão-FACEMA, com número de parecer $\mathrm{n}^{\circ}$ 3.560.519. A maternidade funciona 24 horas para atendimento em urgências obstétricas e neonatal. Possui uma Unidade de Terapia Intensiva Neonatal - UTIN com 07 leitos e uma Unidade de Cuidados Intermediários Convencional - UCINco com 05 leitos.

A população do estudo envolveu os enfermeiros que realizam cuidados direcionados às mulheres em situação de abortamento na instituição. Para a seleção da amostra, foram considerados os seguintes critérios de inclusão: enfermeiros assistenciais e efetivos e como critérios de exclusão: apenas os que estavam de férias ou licença durante a realização da pesquisa.

A maternidade apresenta, no quadro de enfermagem, 22 enfermeiros assistenciais que executam suas atividades como diaristas e plantonistas. Durante a realização da pesquisa, dois enfermeiros encontravam-se de férias e dois em licença saúde e seis recusaram-se participar da pesquisa, totalizando uma amostra final de 12 enfermeiros.

A coleta de dados ocorreu em uma sala privativa da maternidade de acordo com a disponibilidade de cada participante. As entrevistas foram realizadas individualmente, gravadas com uso aparelho MP4® e com duração média de 1 hora. Utilizou-se um roteiro com perguntas direcionadas para caracterização dos entrevistados e guiadas para as questões norteadoras: Quais os principais cuidados de enfermagem no atendimento às mulheres em situação de abortamento? As ações de cuidado realizadas pelos enfermeiros são humanizadas?

Como forma de garantir a segurança aos entrevistados e a ética que rege a pesquisa sobre o sigilo e o anonimato, foi utilizado o pseudônimo ENF (de enfermeiro) em caixa alta com número seguindo de 01 a 12, de acordo com a ordem de realização das entrevistas, com intuito de assegurar o anonimato dos participantes.

Para a análise dos discursos dos participantes, foi empregada a técnica de "Análise de Conteúdo", que é uma estratégia usada para descrever e interpretar informações de documentos e textos. A análise dos dados seguiu as etapas de préanálise, de exploração do material com leituras minuciosas dos conteúdos para extração dos dados pertinentes aos objetivos do estudo e de elaboração das categorias analíticas para discussão dos resultados (Bardin, 2016).

Os dados foram organizados em duas categorias analíticas, a primeira: Principais cuidados de enfermagem às pacientes em situação de abortamento na maternidade e a segunda: Atenção Humanizada dos enfermeiros à mulher em situação de Abortamento na maternidade.

\section{Resultados e Discussão}

\subsection{Caracterização dos sujeitos}

Participaram da pesquisa 12 enfermeiros, sendo que 10 eram do sexo feminino e dois, do masculino. Seis concluíram a graduação em Enfermagem há mais de 10 anos e seis, entre 5 a 10 anos. Dos enfermeiros entrevistados, quatro possuíam especialização em obstetrícia, sete tinham mais de uma especialização e um, nenhuma especialização. Com relação ao tempo 
de serviço, quatro dos entrevistados trabalhavam no hospital entre 7 a 11 anos; cinco, entre 3 a 6 anos e, três há menos de 1 ano.

\title{
3.2 Categorias analíticas
}

\subsubsection{Principais cuidados de enfermagem às pacientes em situação de abortamento na maternidade}

$\mathrm{Na}$ primeira categoria, verificou-se que os principais cuidados realizados pelos enfermeiros às pacientes em situação de abortamento eram voltados ao acolhimento, ao controle da intensidade do sangramento e ao apoio emocional.

Para Cardoso (2017), os cuidados com as pacientes que sofreram abortamento não podem ser praticados de forma mecânica, apenas com procedimentos técnicos, devem ser pautados na assistência integral e de qualidade para amenizar os danos físicos e psicológicos. Os cuidados necessários envolvem as evidências clínicas como sangramento vaginal excessivo, fortes dores abdominais, febre, e outros sinais que caracterizam complicações por abortamento, além dos problemas psicológicos em decorrência do sofrimento e da culpa pela interrupção da gestação.

O esclarecimento do procedimento, a realização do histórico de enfermagem, oferecimento de apoio psicológico e explicação do tipo de medicação utilizada foram os principais cuidados realizados segundo o ENF1.

\begin{abstract}
"Os principais cuidados que a gente tem aqui é primeiramente esclarecer o procedimento [...], vou fazer o histórico de enfermagem, que é a primeira porta de entrada, aonde eu vou saber se ela tem alguma doença ou não; [...], outro cuidado que a gente presta à paciente é oferecer o apoio emocional, porque muitas pacientes que chegam em estágio de abortamento ela está totalmente abalada; [...], o outro cuidado é explicar também a medicação, como é que ela vai funcionar no organismo da pessoa, porque aqui os médicos passam misoprostol quando a paciente tá o colo fechado pra tentar dilatar esse colo e poder fazer curetagem, que a gente chama de misiprostol, então a gente explica também como é que vai ser mais ou menos o funcionamento dessa medicação. (ENF1)
\end{abstract}

Segundo a Norma Técnica do Ministério da Saúde (MS), no atendimento emergencial da mulher em situação de abortamento, os enfermeiros realizam a classificação de risco, avaliando inicialmente os sinais vitais com intuito de averiguar a gravidade da situação. No caso de verificação de alteração na coloração da pele, na pressão arterial e frequência cardíaca com sangramento abundante, dor intensa, febre, calafrios ou mal-estar geral são sinais de agravamento do quadro clínico da mulher. Para tanto, condutas imediatas devem ser adotadas para restabelecer os sinais vitais e evitar complicações maiores (Brasil, 2014).

De acordo com Garcia (2016), os enfermeiros devem utilizar o Processo de Enfermagem (PE) como instrumento inicial para o estabelecimento das prioridades de cuidado. O PE é fundamental para a identificação dos sinais e sintomas do paciente, do planejamento e de implementação das ações de cuidado e da avaliação dos resultados. Por meio dele, os enfermeiros fazem a prescrição de Enfermagem de forma individualizada, melhoram os registros de Enfermagem e a humanização do cuidado.

Segundo Martino, Fogaça, Costa e Toledo (2014), a aplicação do histórico de enfermagem com etapa inicial do PE deve ser realizada por meio de uma entrevista guiada com linguagem clara e concisa com perguntas simples e objetivas, respeitando o direito das pacientes em responder ou não às perguntas e em relatar ou não o ocorrido, isentando-se de fazer julgamentos e de ter atitudes preconceituosas sobre o aborto. A importância da realização do Histórico de Enfermagem é conhecer o quadro clínico da paciente e planejar as intervenções necessárias. Para tanto, nesse momento, a entrevista deve ser guiada com linguagem clara e concisa por meio de perguntas simples e objetivas, respeitando o direito das pacientes em responder ou não às perguntas e em relatar ou não o ocorrido, isentando-se de fazer julgamentos e de ter atitudes preconceituosas sobre o aborto

De acordo com as falas dos ENF2, ENF4, ENF7, ENF8, ENF10 e ENF11, os enfermeiros utilizam o acolhimento como principal cuidado prestado à mulher que chega em situação de abortamento. 
Principal cuidado, primeiro [...] a gente acolhe essa mulher né, ouve a mulher, explica os sinais de perigo de acordo com a situação de abortamento [...] aí classifica e encaminha ela, encaminho ela pra um especialista, no caso um médico obstetra vai avaliar pra saber se ela vai ficar internada ou não. (ENF2)

Todas as pacientes admitidas no hospital, [...] elas são acolhidas primeiramente, depois de fazer o acolhimento, nós iniciamos a nossa sistematização da assistência de enfermagem, fazendo o histórico de enfermagem, levantando diagnóstico [...] orientamos ela ficar em repouso, comunicar qualquer coisa que ela tenha, sangramento, dores, a gente faz o medicamento que tá prescrito né, administra esses medicamentos e aguarda o momento de curetagem [...] normalmente tentamos deixar essas mulheres separadas de outras que estão com os seus bebes, pra não causar tristeza nela. (ENF4)

Como qualquer paciente que estiver em situação de risco, tem que seguir o ABCD, E. E no caso, os sinais vitais, respiração [...] observar a questão religiosa, que é muito forte, dar acolhimento, dar apoio emocional, dar suporte pra essa mulher [...] ]então não somente ver os sinais vitais, observar sangramento, observar os sinais de infecção ou outra coisa do tipo [...]Dar um suporte também emocional e psicológico pra essa mulher, e de preferência também tá referenciando ela pra esses profissionais que podem dar esse suporte. (ENF7)

Os principais cuidados é o acolhimento [...] a gente realiza a sistematização da assistência de enfermagem e nós acompanhamos o procedimento no centro cirúrgico né, a curetagem uterina né, até ela ser transferida pro posto, onde ela vai se recuperar pelas 24 horas. (ENF8)

Acolhimento, acolher a paciente, fazer a escuta, a escuta qualificada, uma escuta sem julgamentos [...] (ENF10)

[...] Acolhimento né, onde é feito a abordagem inicial e alguns exames iniciais como o teste, testes rápidos de sífilis e HIV , e depois essa paciente é encaminhada pra enfermaria de tratamento clinico, onde vai ser conduzido de acordo com a situação dela né, se é um abortamento completo, incompleto [...]. (ENF11)

Segundo Oliveira, Nunes e Silva (2014), o acolhimento é um dos itens indispensáveis quando se trata do cuidar de pessoas. Conforme preconiza o MS pela Norma Técnica de Atenção Humanizada ao Abortamento, o acolhimento é um instrumento de coleta de dados que se inicia desde o primeiro contato que essa mulher tem com o serviço de saúde. É nesse momento que ela pode expressar seus sentimentos de culpa, medo, desespero, angústia, entre outros e, para que haja troca de informações relevantes no processo terapêutico, o profissional deve estar preparado para atendê-la (Brasil, 2011).

Postingher (2018) coloca que na presença de evidências do abortamento, tais como, sangramento, dor no baixo ventre e descompensação dos sinais vitais, deve-se seguir um protocolo de atendimento em consonância com esses achados. Nessas circunstâncias, ainda na visão desse autor, a depender do grau de sangramento solicita-se restrição da dieta, ou seja, é necessário que a paciente permaneça de jejum caso haja uma necessidade posterior de realização de procedimento cirúrgico.

$\mathrm{Na}$ fala do ENF3, observou-se que alguns dos cuidados realizados foram verificação dos sinais vitais e orientação do jejum antes da realização da curetagem.

Segundo Pierotti et. al., (2018), o jejum é um evento preconizado antes da realização da curetagem ou de qualquer procedimento cirúrgico. O paciente deve ficar no mínimo seis horas sem se alimentar para que haja o esvaziamento total do estômago e assim diminuir os riscos de intercorrências como vômitos e broncoaspiração durante a intervenção cirúrgica.

Assim, os principais cuidados são em relação a sinais vitais, é orientar o jejum, é porque a maioria das pacientes elas vão fazer curetagem, então tem que tá com jejum de pelo menos 6 horas, e observar a questão do sangramento transvaginal na paciente. (ENF3)

Segundo Ribeiro, Ribeiro, Machado e Machado et. al., (2015), a curetagem uterina é um procedimento obstétrico cirúrgico indicado à mulher em processo de abortamento. É indicado como método de esvaziamento do útero em casos de aborto incompleto, sendo o segundo procedimento mais realizado pelo Sistema Único de Saúde (SUS).

Nas falas dos ENF5, ENF6, ENF9 e ENF12, foi evidenciado que um dos principais cuidados realizados por eles estava voltado para a observação da intensidade e da coloração do sangramento. Para Garcia (2015), o sangramento é um sinal 
esperado durante o processo de abortamento; a intensidade do sangramento sugere clinicamente o tipo de aborto que essa mulher está sofrendo como exemplo, na ameaça de aborto, o nível de sangramento pode ocorrer com baixa intensidade precedido ou não de cólicas.

Em primeiro lugar a gente vai observar a intensidade do sangramento, observar o sangramento, a coloração e a questão também da dor, que é avaliada também, logo em seguida a gente vê os sinais vitais e a gente encaminha logo ao médico. (ENF5)

[...] a gente presta os cuidados de pós- operatórios né, comum a todos os pacientes daqui, questão do sangramento, questão da dor, a gente faz né, recebe, faz admissão, pergunta se a paciente tá sentindo alguma coisa, e observa a questão do sangramento, se tá intenso, e fica em observação, até ela ser avaliada, reavaliada pelo obstetra, no caso. (ENF6)

É a questão de, é cuidados em questão do observar sangramento, apoio psicológico, eu acho que só. Os risco né, de infecção. (ENF9)

[...] Observo sangramento, escuto as queixas né, no caso, antes da curetagem a gente vai observando sangramento, aqueles que for preciso usar misoprostol pra induzir [...] observar se tem acesso venoso, são os cuidados básicos que a gente prestaria com qualquer paciente [...] (ENF12)

O sangramento é um dos sintomas típicos apresentado pela mulher com quadro de abortamento. Segundo Mattos (2015), os cuidados nesse momento são o monitoramento do sangramento e/ou a infecção uterina. No caso de persistência do sangramento, deve ser solicitado ao médico a prescrição de uterotônicos, ou avaliação médica para realização da aspiração manual intrauterina (Amiu) conforme a situação apresentada.

Em decorrência do aumento do número de casos de abortamento no Brasil, é necessária a implantação de um protocolo específico ao cuidado à mulher em situação de abortamento em todas as maternidades ou serviços de saúde, enfatizando as ações da enfermagem e definindo os papéis dos profissionais envolvidos.

Nesta categoria ficou evidenciado que a maioria dos enfermeiros executa os cuidados de forma integral e qualificada, porém percebeu-se que alguns não citaram o Processo de Enfermagem como instrumento necessário no acolhimento e no cuidado às mulheres.

\subsection{Humanização dos cuidados dos enfermeiros às mulheres em situação de Abortamento na maternidade}

Esta categoria aborda a humanização das ações de enfermagem às mulheres que buscam atendimento na condição de aborto na maternidade.

Tavares e Mafra (2018) afirmam que o cuidado humanizado tem correlação direta com o respeito e a compreensão das necessidades de cada indivíduo, concebendo autonomia para que cada pessoa exponha suas vontades e desejos, observando a singularidade e suas crenças, excluindo os julgamentos pré-concebidos. Sendo assim, é a forma mais eficaz de resguardar a virtude humana.

Verificou-se pelas falas dos ENF1, ENF2, ENF3, ENF4, ENF6, ENF7 e ENF8 que os cuidados realizados pelos enfermeiros às mulheres em situação de abortamento eram humanizados.

[...] São todas humanizadas, sim, todos os enfermeiros tem o maior cuidado com a paciente, em tá fornecendo apoio pra elas nesse momento tão difícil que é essa fase de abortamento, então assim, a gente tenta chamar a paciente pelo nome a todo momento, as pacientes elas são identificadas quando chega aqui na maternidade elas têm uma pulseirinha onde identifica, então quando a gente chega perto dessa paciente a gente tenta falar pelo nome, a gente tenta conversar com as pacientes[...], se ela quiser conversar alguma coisa, muita delas não tem acompanhante né, aqui a gente tem direito a um acompanhante todas as pacientes independente que seja pra parto, abortamento, todas as pacientes tem direito a um acompanhante, mas muita delas não tem ninguém pra vim acompanhar elas[...f, então 
pra mim isso é uma humanização, a partir do momento que eu vou dar esse apoio emocional a essa paciente é humanização[...].(ENF 1)

São humanizadas, porque nós atendemos essa mulher independente da situação que ela esteja[...]. Do nosso acolhimento, do nosso cuidado holístico, da nossa integralidade da nossa assistência, então se a gente não conseguir fazer os princípios do sus acontecer aqui, de nada será feito né, então nós tentamos fazer a questão da integralidade, da universalidade dos direitos, da equidade que é um princípio bem norteador do sus, a gente consegue aqui dentro da maternidade Wall Ferraz fazer isso acontecer. (ENF 2)

Sim, aqui toda a assistência prestada na maternidade é uma assistência humanizada, é a paciente ela recebe todas as informações possíveis, orientação, acompanhamento de perto por toda a equipe médicas e de enfermagem e os leitos também ele tem o mínimo de privacidade pra paciente. (ENF 3)

É nós tentamos fazer com que seja mais humanizado possível, primeiro que a gente tenta deixar elas num local mais reservado, numa enfermaria reservada apenas pra esses casos, e para tratamentos clínicos, pra que ela não se sin...não se sensibilize mais ainda vendo outros bebês né, mães com outros bebês, é o...tentamos ela tem o direito a acompanhante. (ENF 4).

Assim, eu acredito que sim, porque aqui ela tem todo, é. Tem todo um amparo, a gente né, tem, a gente conversa com a paciente né, como eu já disse, pergunta se tá tudo bem, se ela tá sentindo alguma coisa, tem paciente que é, né, mais conformado, que estão mais, perguntam muita coisa, vão perguntando perguntando, a gente procura responder na medida do possível, e, basicamente é isso[...]. (ENF 6)

Na unidade de trabalho a qual eu estou inserido, eu percebo que existe essa humanização, e... sempre com olhar mais holístico né, voltado pra integridade dessa mulher, não somente física, mas também psicológica, mental e mais recentemente a gente tem tentado cada vez mais incluir a parte espiritual, porque o papel da mulher é... E a situação dela diante de várias religiões é diferente, eles tem dogmas, né, existem verdades que são inquestionáveis, e tudo isso a gente tem que tá respeitando, mais ao mesmo tempo não esquecendo de fornecer o apoio que ela tanto precisa, então eu vejo como humanizados as práticas aqui[...] (ENF 7)

Sim, a gente começa pelo acolhimento, num é, então aqui elas são, elas são muito bem tratadas, tratadas com respeito né, elas têm direito a um acompanhante, e assim, e todas as práticas são realizadas seguindo a política de humanização, com certeza, aqui sim. (ENF 8)

A Norma Técnica sobre atenção humanizada ao abortamento coloca que os cuidados devem ser implementados para garantir a segurança das pacientes e a efetivação dos cuidados, sendo necessária a incorporação de elementos primordiais nos serviços de saúde como acolhimento e orientação, atenção clínica satisfatória ao abortamento e as possíveis complicações, seguindo os aspectos éticos, legais e morais dessa mulher. Devem ser ofertadas, também, orientações sobre planejamento reprodutivo no pós-abortamento para aquelas mulheres que ainda desejam engravidar, ou aquelas que não desejem ter filhos passem a adotar métodos de contracepção para evitar novos abortos (Brasil, 2011).

É essencial que as ações de enfermagem utilizem a humanização como base na prestação do cuidado e na percepção da valorização do ser humano. Segundo Souza e Silveira (2019), a escuta qualificada é uma medida de cuidado humanizado que pode ser adotada pelos profissionais de saúde e, em especial, pelos enfermeiros, que passam maior parte do tempo com os pacientes. Durante a realização da escuta, os enfermeiros devem estar preparados para ouvi-las e ajudá-las a enfrentar essa situação. Verificou-se no depoimento do ENF10 que ele abordou a necessidade de usar a escuta qualificada para prestação do cuidado humanizado.

São, são humanizadas, porque a gente faz a escuta, a gente procura entender o contexto daquela, daquela mulher, a gente procura entender o contexto social dela, o contexto familiar, o que seria aquela gravidez na vida daquela mulher naquele momento dela né, como é que de qualquer forma ela absorve esse, esse, essa perda, como é a questão do luto né, e a gente procura também direcionar trabalhar, vivenciar com ela a absorção dessa dor[...] (ENF 10) 
Sousa, Costa Filha, Costa, Castro e Lando (2017) colocam que uma assistência humanizada requer profissionais inteirados quanto às questões técnicas, legais e éticas relacionadas ao aborto, cessando qualquer relação preconceituosa e com julgamentos pré-concebidos. Nessa perspectiva, o diálogo é instrumento indispensável para uma instrução palpável, representando um embasamento para a classe de profissionais, sendo apontada nos princípios éticos, técnicos e jurídicos de assistência humanizada ao processo de aborto.

O ENF1 colocou que a participação do acompanhante durante a internação da mulher faz toda a diferença no enfrentamento da situação de abortamento e na melhoria do aspecto emocional.

[...] se ela quiser conversar alguma coisa, muitas delas não têm acompanhante né, aqui a gente tem direito a um acompanhante. Todas as pacientes independente que seja pra parto, abortamento, todas as pacientes têm direito a um acompanhante, mas muitas delas não têm ninguém pra vim acompanhar elas[...], então pra mim isso é uma humanização, a partir do momento que eu vou dar esse apoio emocional a essa paciente é humanização[...].(ENF 1)

Segundo Souza e Gualda (2016), no momento de internação da mulher, o acompanhante desempenha um papel de extrema importância, dentre eles: tranquilizar, trazer aconchego, propagar incentivo e coragem, transmitir segurança e entreter. O auxílio emocional que ela recebe tem eficácia e propicia um suporte a tensão e a dor, além de induzir a mulher a dar seguimento adequado à assistência oferecida pelos profissionais de saúde (Pereira \& Souto, 2018).

No depoimento do ENF11, foi evidenciado que muitos profissionais ainda não realizam a humanização durante a prestação de cuidado às mulheres na maternidade.

Assim, a meu ver, atualmente né, apesar da gente ter uma política nacional de humanização, mas depende muito do profissional. Infelizmente ainda não é uma prática adotada por todos na nossa realidade, depende muito da equipe mesmo, às vezes é um médico mais acessível, mas o enfermeiro e os técnicos não são, depende muito infelizmente do profissional, mas aqui a gente tem muitos profissionais que trabalham de forma humanizada, mas infelizmente não são todos. (ENF 11)

O enfermeiro participa de todo o processo de saúde bem próximo do usuário e, por isso, fica sob incumbência de assegurar a modificação do cuidado que ainda esteja baseado no modelo biomédico e positivista para uma prestação de serviços humanizados (Toral et al., 2019).

No entanto, verificou- se ainda que existem algumas dificuldades para que a assistência seja eficazmente humanizada. No depoimento do ENF5, observou-se que o enfermeiro não sabia se as práticas realizadas pelos médicos para retirada do feto morto eram de fato humanizadas. Na fala, ela disse que um dos médicos dilatava o colo e administrava o misoprostol, enquanto o outro orientava o jejum para realização de curetagem uterina e utilizava anestesia raqui para o procedimento.

Olha, a maioria dos procedimentos que eu...que eu observo aqui no hospital, eles são um abortamento induzido, tipo assim, ela já fazem ultrassom, for detectado feto morto, elas ficam internadas e faz a gente não...os médicos administram o niso, e observa, a questão de aumentar mais o volume, se o colo dilatou, eu não sei se essa seria uma prática né...humanizada, porque eu já vi um outro médico descordando dessa prática, ele já faz é...já é anestesia aqui e, tipo assim, não não fica esses...essa paciente com muito tempo em jejum, elas não sofre a dor do que a medicação provoca, então logo detectado ela fica em jejum umas 6 h ou menos e vai pro centro cirúrgico, pra anestesia raqui e faz o procedimento, esse médico ele é mais de acordo com essa prática, agora de dizer qual é o mais humanizado é complicado. (ENF 5)

Segundo o Ministério da Saúde, é necessário que a escolha do tipo de método para a realização do abortamento seja uma decisão compartilhada entre a mulher e o médico. Para tanto, cabe aos médicos e aos enfermeiros esclarecerem a mulher, o método escolhido e os cuidados necessários para realização do procedimento. De acordo com a norma técnica da Atenção humanização ao abortamento, cabe a todos os profissionais de saúde que assistem diretamente essas mulheres promover ações 
de acolhimento de qualidade, esclarecer os cuidados necessários, orientar e fornecer suporte emocional durante o tempo de internação no serviço de saúde (Brasil, 2014).

Dois enfermeiros (ENF9 e ENF 12) relataram que os atendimentos às pacientes em situação de aborto não eram integralmente humanizados, visto que havia alguns pontos que precisavam ser ajustados na prestação da assistência, como apoio emocional, cuidados específicos para as mulheres, enfermarias próprias e, ainda, a garantia do sigilo das informações das pacientes. Todos esses fatores comprometem a qualidade do serviço, pois mostra que o cuidado não é oferecido conforme o preconizado pela Política Nacional de humanização (Brasil, 2015).

Não, rsrsrs.. Não são. Devia ter mais suporte emocional, do suporte psicológico. São, são. E também, mais também questão de sigilo também, às vezes. (ENF 9)

eu acho que não, assim, num tem nada, como num tem nada nenhum cuidado especifico para as mulheres em abortamento, teve até uma enfermeira daqui que fez um trabalho querendo colocar uma enfermaria específica para as pacientes de curetagem, chegou a iniciar né, a gente deixava, assim, não a enfermaria lá é pra colocar as pacientes no pós curetagem, pra não misturar elas com outras pacientes no pós parto normal, pós parto cesáreo, que tivessem neném né, [...], então aqui as pacientes de pós curetagem elas ficam misturadas com outras pacientes [...], eu lembro que uma vez essa paciente era a segunda perda e ela tava chorando muito e ela disse que não queria ficar com outras pacientes que tivessem bebê, então a gente deixou ela numa enfermaria de tratamento clínico, colocou ela em outro posto, não era costume colocar mais foi feito né,[...], então isso pra mim é uma pratica humanizada[...](ENF 12)

De acordo com Corrêa, Souza e Santo (2018), muitos profissionais de saúde não percebem as particularidades de cada paciente, só julgam as informações pertinentes no momento que veem algum vestígio. É essencial que a equipe de enfermagem esteja preparada para ofertar uma assistência de qualidade e integral a mulher independente do quadro clínico apresentado.

\section{Conclusão}

Os resultados do estudo mostraram que os principais cuidados realizados pelos enfermeiros às pacientes em situação de abortamento eram voltados ao acolhimento, ao controle da intensidade do sangramento e ao apoio emocional. Foi verificado que apenas um enfermeiro utilizava o Processo de Enfermagem na prestação dos cuidados. Quanto à atenção de cuidados humanizados destinados às mulheres em situação de abortamento, verificou-se que nem todos os profissionais desempenhavam os cuidados de forma humanizada, principalmente voltados aos aspectos psicológicos.

Para que os cuidados às mulheres sejam integrais e humanizados como proposto pela Norma Técnica Humanizada ao abortamento do SUS, é necessário que todos os profissionais de saúde e, especialmente, os enfermeiros estejam integrados tanto na prestação de cuidados físicos, com embasamento técnicos, éticos e jurídicos na área do aborto, quanto nos cuidados psicológicos, com escuta qualificada, afetividade e o acolhimento.

Diante dos resultados, espera-se que os profissionais de saúde, em especial os enfermeiros, desenvolvam ações de acolhimento com escuta qualificada, de orientação sobre as condutas clínicas e de planejamento reprodutivo pós-abortamento. É essencial que as ações de enfermagem utilizem a humanização como base na prestação do cuidado e na percepção da valorização do ser humano.

\section{Referências}

Bardin, L. (2016). Análise de conteúdo.

Corrêa A. M. G. D., Souza A. C., \& Santo M. C. B. E. (2018). Humanização na unidade de terapia intensiva: vivência da equipe de enfermagem. UNIVAG Centro Universitário: http://www.repositoriodigital.univag.com.br/index.php/enf/article/view/35/36

Freitas, J. S., Camargo Silva, A. E. B., Minamisava, R., Bezerra, A. L. Q., \& Sousa, M. R. G. (2014). Qualidade dos cuidados de enfermagem e satisfação do paciente atendido em um hospital de ensino. Revista Latino-Americana de Enfermagem, 22(3), 454-460. 
Garcia, C. A.O. (2015). Protocolo Clínico: Abortamento. Maternidade-Escola Assis Chateaubriand - MEAC, Universidade Federal do Ceara - UFC: http://www2.ebserh.gov.br/documents/214336/1109086/PRO.OBS.001+-+REV1+ABORTAMENTO.pdf/e43700cc-dca5-49b6-a69d-808e5294784f

Garcia, T. R. (2016). Sistematização da assistência de enfermagem: aspecto substantivo da prática profissional. Esc Anna Nery Rev Enferm [Internet], 20 (1): $5-10$.

Lima, L. M., Gonçalves, S. D. S., Rodrigues, D. P., Araújo, A. D. S. C., Correia, A. D. M., \& Viana, A. P. D. S. (2017). Cuidado humanizado às mulheres em situação de abortamento: uma análise reflexiva. Rev enferm UFPE, 5074-5078.

Maranhão, T. A., Gomes, K. R. O., \& Barros, I. D. C. (2016). Fatores preditores do abortamento entre jovens com experiência obstétrica. Revista Brasileira de Epidemiologia, 19, 494-508.

Martino, M. M. F., Fogaça, L. F., Costa, P. C. P., \& Toledo, V. P. (2014). Análise da aplicação do processo de enfermagem em um hospital governamental. Rev Enferm UFPE On Line, 8(5), 1247-53.

Mattos, S. B. (2015). Causas relacionadas ao aborto expontâneo: uma revisão de literatura. 41 f. Tese (Especialista) Universidade do extremo sul catarinense UNESC. Especialização em enfermagem obstétrica e neonatal. Criciúma - SC: http://repositorio.unesc.net/bitstream/1/3300/1/Silvia\% 20Barbosa\%20Mattos.pdf

Ministério da Saúde. (2011). Secretaria de Atenção à Saúde. Departamento de Ações Programáticas Estratégicas. Atenção humanizada ao abortamento: norma técnica. Ministério da Saúde, Secretaria de Atenção à Saúde, Área Técnica de Saúde da Mulher. (2a ed.): http://bvsms.saude.gov.br/bvs/publicacoes/atencao_humanizada_abortamento_norma_tecnica_2ed.pdf

Ministério da Saúde. (2014). Secretaria de Atenção à Saúde. Departamento de Ações Programáticas Estratégicas. Atenção humanizada ao abortamento: norma técnica / Ministério da Saúde, Secretaria de Atenção à Saúde, Área Técnica de Saúde da Mulher. - (2a ed.), Ministério da Saúde. https://www.arca.fiocruz.br/bitstream/icict/29903/2/ATEN\%C3\%87\%C3\%83O\%20HUMANIZADA\%20AO\%20ABORTAMENTO.pdf

Ministério da Saúde. (2015). Secretaria de Atenção à Saúde. Política Nacional de Humanização. Brasília-DF. http://bvsms.saude.gov.br/bvs/publicacoes/politica_nacional_humanizacao_pnh_folheto.pdf

Oliveira, N. P. D., Nunes, L. R., \& Silva, R. D. C. V. D. (2014). Acolhimento nos serviços públicos de saúde às mulheres em situação de aborto provocado. Paes B., Borges E., Rocha J. (2018). Breve panorama sobre aborto legal e transparência no Brasil. São Paulo.

Pierotti, I., Nakaya, T. T., Garcia, A. K. A., do Nascimento, L. A., Conchon, M. F., \& Fonseca, L. F. (2018). Avaliação do tempo de jejum e sede no paciente cirúrgico. Revista Baiana de Enfermagem32.

Postingher M. (2018). Protocolo de atendimento a mulheres em situação de abortamento. 96 f. Tese (Mestrado) Universidade do Valo do Rio dos SinosUNISINOS, Programa de Pós-graduação em Enfermagem, Porto Alegre. http://www.repositorio.jesuita.org.br/bitstream/handle/U NISINOS/7145/Mariana\%20Postingher_.pdf?sequence=1\&isAllowed=y

Ribeiro, J. F., Ribeiro, L. S., Machado, P. H. F., \& Machado, T. M. G. (2015). Perfil das mulheres submetidas à curetagem uterina pós-abortamento em um hospital público. Gestão e Saúde, 6(2), Pag-1354.

Rodrigues, W. F. G., Andrade, D. C. D., Dantas, S. A., \& Silva, L. R. D. (2017). Abortamento: protocolo de assistência de enfermagem: relato de experiência. Rev enferm UFPE on line, 3171-3175.

Santana, D. M., Santos, R. S., \& Pérez, B. A. (2015). A assistência de Enfermagem à mulher em processo de abortamento. Revista Psicologia, Diversidade e Saúde, 3(1).

Silva, E. F. D., Trevisan, D. C., Lorenzini, E., Pruss, A. C. D. S. F., Strapasson, M. R., \& Bonilha, A. L. D. L. (2015). Atenção à mulher em processo de abortamento induzido: a percepção de profissionais de enfermagem. Rev. enferm. UFSM, 454-464.

Soares F. P., Feliciano R. M., Gobira R. A. (2018). Atenção Humanizada à Mulher em Processo de Abortamento no Mesmo Ambiente das Parturientes. Rev Eletrôn Atualiza Saúde, 7(7), 95-99.

Sousa, E. M., Filha, F. S. S. C., da Costa, L. S., de Castro, R. D. P., \& Lando, G. A. (2017). Abortamento x direitos do nascituro: Concepções de profissionais de saúde atuantes em Maternidade. Revista Ciência \& Saberes-UniFacema, 3(2), 484-491.

Souza, S. A. L. D., \& Silveira, L. M. C. D. (2019). (Re) Conhecendo a escuta como recurso terapêutico no cuidado à saúde da mulher. Revista Psicologia e Saúde, 11(1), 19-42.

Souza, S. R. R. K., \& Gualda, D. M. R. (2016). A experiência da mulher e de seu acompanhante no parto em uma maternidade pública. Texto \& ContextoEnfermagem, 25(1).

Strefling, I. D. S. S., Lunardi Filho, W. D., Demori, C. C., Soares, M. C., \& dos Santos, C. P. (2015a). Cuidado de enfermagem à mulher em situação de aborto: revisão integrativa. Revista de Enfermagem da UFSM, 5(1), 169-177.

Strefling, I. D. S. S., Lunardi Filho, W. D., Kerber, N. P. D. C., Soares, M. C., \& Ribeiro, J. P. (2015b). Percepções da enfermagem sobre gestão e cuidado no abortamento: estudo qualitativo. Texto \& Contexto-Enfermagem, 24(3), 784-791.

Taquette, S. R., \& Villela, W. V. (2017). Balizas do conhecimento: análise das instruções aos autores das revistas brasileiras da área de saúde. Ciência \& Saúde Coletiva, 22, 7-13.

Tavares M. M. S., \& Mafra, C. R. (2018). A assistência de enfermagem diante da humanização do parto. 23 f. Tese (Bacharel) Faculdade de Ciências da Educação e Saúde-FACES. Centro Universitário de Brasília-UniCEUB. Brasília: https://repositorio.uniceub.br/jspui/bitstream/prefix/13037/1/21486083.pdf 
Research, Society and Development, v. 10, n. 2, e2510212051, 2021

(CC BY 4.0) | ISSN 2525-3409 | DOI: http://dx.doi.org/10.33448/rsd-v10i2.12051

Toral, A., Vilain, C. R. F., Morais, T., Valcarenghi, R. V., Correia, J. B. B., \& Ponciano, T. C. L. (2018). Assistência de enfermagem na humanização do parto: uma revisão integrativa. Revista Eletrônica Estácio Saúde, 8(1), 45-53. 